ПОНЕДЕЛКОВ Александр Васильевич - доктор политических наук, профессор; заведующий кафедрой политологии и этнополитики Российской академии народного хозяйства и государственной службы при Президенте РФ (119571, Россия, г. Москва, пр-кт Вернадского, 82, cmp.1; ponedelkov@ skags.ru); заслуженный деятель науки РФ

ВОРОНЦОВ Сергей Алексеевич - доктор юридических наук, профессор кафедры процессуального права Российской академии народного хозяйства и государственной службы при Президенте РФ (119571, Россия, г. Москва, пр-кт Вернадского, 82, cmp. 1; raven_serg@таil.ru)

ОХОТСКИЙ Евгений Васильевич - доктор социологических наук, профессор кафедры государственного управления факультета управления и политики Московского государственного института международных отношений (университет) МИД России, советник дипломатической службы РФ 2-го класса (119454, Россия, г. Москва, пр-кт Вернадского, 76; e.ohotskii@mail.ru)

ВАСЬКОВ Максим Александрович - доктор социологических наук, профессор, ведущий научный сотрудник лаборатории проблем повышения эффективности государственного и муниципального управления Российской академии народного хозяйства и государственной службы при Президенте РФ (119571, Россия, г. Москва, пр-кт Вернадского, 82, стр. 1; vaskovmaxsim@таil.ru)

\title{
РОССИЙСКАЯ ЭЛИТОЛОГИЯ: ИННОВАЦИОННЫЕ ОТВЕТЫ НА ВЫЗОВЫ СОВРЕМЕННОГО МИРА
}

Аннотация. В статье исследуются возможные инновационные ответы со стороны российской элитологии на вызовы современного мира, анализируются результаты социологического исследования, продолжающего многолетнюю научную традицию ростовской научной элитологической школы по изучению социального статуса, роли и базовых характеристик современной российской правящей элиты, тенденций и проблем ее развития и функционирования. Авторы формулируют комплекс мер, направленных на решение прикладных задач и разработку практических рекомендаций по устранению проблем, возникающих в ходе государственного и муниципального управления.

Ключевые слова: элиты, конгресс, социологическое исследование, эксперты, выводы, предложения

$\mathrm{B}^{\mathrm{r}}$ г. Ростове-на-Дону 15-16 февраля 2019 г. планируется провести Третий элитологический конгресс «Российская элитология: инновационные ответы на вызовы современного мира». В рамках подготовки к конгрессу проведено социологическое исследование, продолжающее многолетнюю научную традицию ростовской научной элитологической школы по изучению социального статуса, роли и базовых характеристик современной российской правящей элиты, тенденций и проблем ее развития и функционирования. Изучение указанных выше проблем организовано в контексте реальных социально-политических процессов. По аналогичной методике проводилось исследование в связи с подготовкой Первого элитологического конгресса «Элитология России: современное состояние и перспективы развития» [Рудой и др. 2013] и Второго конгресса, который был посвящен проблематике под общим названием «Элитология и стратегии развития современной России» [Локота и др. 2016].

Несмотря на, казалось бы, небольшой временной интервал, в рамках которого состоялись указанные выше конгрессы, они, тем не менее, проводились в принципиально различных социально-политических условиях. 2013 г. - время стабильности, мало чем предвещающее затяжной кризис, который охватил практически все сферы и все аспекты жизни российского общества. Не исключено, что со временем он может приобрести глобальный характер. Исследование, которое проведено в 2018 г., - это социологический анализ в кардинально изменившихся условиях даже по сравнению с 2016 г. Российской 
элите и обществу предстоит решать не просто текущие проблемы жизнедеятельности общества, а вопрос сохранения государства вообще. В обстановке конфронтации, безудержной русофобии и беспрецедентного санкционного давления, в условиях, как говорит В.В. Путин, пренебрежения существующими нормами и утраты взаимного доверия, которые «могут наложиться на непредсказуемость, турбулентность колоссальных технологических перемен» ${ }^{1}$, практически неизбежен системный кризис, с которым мир еще не сталкивался или давно уже не сталкивался. Тревожных тенденций немало: на глазах всего человечества подрывается стабильность деловых связей, усиливаются дезинтеграционные процессы, девальвируются формы многостороннего сотрудничества, падает эффективность международных институтов и соглашений.

Современная элита функционирует в обществе в двух основных ипостасях. В спокойные и благоприятные времена это достаточно рутинная реализация политико-управленческих функций и поддержание стабильности и преемственности уже существующих государственного и общественного механизмов. Во время кризисов, тем более отличающихся глубиной, продолжительностью, системным охватом всех сфер жизни общества и государства, ярко выраженной внутренней и внешней угрозой и необходимостью защищать свои основополагающие принципы и цивилизационный выбор, функции и задачи элиты меняются. Тем не менее можно говорить об актуализации классического набора функций элиты, который был представлен еще в работе А.Дж. Тойнби: чтобы доказать свою состоятельность и вообще право не просто считаться, а быть элитой страны, нужно принимать вызов и, стратегически осмыслив положение страны, найти на него эффективный ответ, пережив стадию надлома и не допустив перехода к стадии дезинтеграции и распада [Тойнби 1991:106].

Другим фактором являются уже обозначившиеся негативные тенденции взаимодействия политико-управленческой элиты и общества, включая последствия пенсионной реформы, когда необходимо брать ответственность за непопулярные решения. Понятно, что в таких непростых условиях требуется не только профессионализм и глубокое понимание ситуации, но и способность взять на себя ответственность за принимаемые решения.

Социологическое исследование 2018 г. включало в себя изучение регионов с различающейся социальной, культурной, политической и экономической спецификой. Задача: исследовать состояние элиты и элитологической науки с разных точек зрения, выявить лидеров общественного мнения, их влияние на происходящие в обществе процессы. География исследования: Ростовская, Архангельская, Московская, Ленинградская обл., Республика Коми, Краснодарский, Ставропольский края, Курганская обл., республики Адыгея, Коми, Северная Осетия-Алания, Кабардино-Балкария, Карачаево-Черкессия, Ингушетия, Чеченская Республика. В целом социологическим опросом были охвачены более 1000 экспертов - государственных деятелей, депутатов, руководителей органов исполнительной власти, партийных лидеров, наиболее авторитетных представителей СМИ, ученых и преподавателей высшей школы.

Эксперты имеют свое определенное представление о характере генезиса элиты. По их мнению, элита региона сформирована федеральной властью из числа нужных ей людей. Такого мнения придерживаются 44,0\% экспертов. Современная элита представлена в основном бывшей номенклатурой, быстро сменившей прежнюю идеологическую принадлежность, и новым поколением, состоящим из их родственников (40,0\%). В 2014 г. так считали 37,0\% экспертов.

1 Путин В.В. 2018. Выступление на пленарном заседании Петербургского международного экономического форума. 25 мая 2018 г. Санкт-Петербург. Доступ: http://www.kremlin.ru/events/president/ news/57556 (проверено 25.11.2018). 
Хотя можно отметить, что понятие «бывшая номенклатура» уже лишено того смысла, который вкладывался в это понятие в 1990-е гг.

Эксперты отметили, что процесс формирования региональной элиты по-прежнему является результатом внутриэлитных договоренностей и клановых политико-управленческих отношений $(34,0 \%)$. И лишь $18 \%$ экспертов считают, что формирование региональной элиты происходит посредством демократических процедур. Некоторые эксперты (8\%) полагают, что сейчас в регионах у власти находятся творческие и активные люди, у которых много замыслов, искреннее желание изменить ход событий в лучшую сторону, но усилия таких руководителей серьезно блокируются высшей государственной властью и коррумпированными структурами.

Для системного понимания процессов, связанных с элитой как со средой, где осуществляется процесс разработки и принятия ключевых решений, необходимо сравнить результаты 2018 г. с результатами исследования 2016 г. Так, заслуживает внимания трансформация в ответах на вопрос: «Какие меры Вы бы предложили для улучшения качественных характеристик современной правящей российской элиты?» Бросается в глаза снижение значимости фактора антикоррупционного очищения - с 49,5\% до 46,0\%. Можно предположить, что это связано не с определенной результативностью принимаемых антикоррупционных мер, а с широким освещением в СМИ процессов, связанных с пресечением коррупционных преступлений должностных лиц. Можно также говорить о реальном применении в последние годы принципа неотвратимости наказания за совершенные преступления и равенства каждого перед законом.

На первом месте по значимости остаются показатели персональной ответственности должностных лиц, ужесточения спроса за некачественное исполнение служебных обязанностей - 58,0\%. Респонденты отмечают необходимость смены фактической анонимности власти как бюрократической управленческой машины ее персонификацией в плане профессионализма и ответственности за результат управленческой работы. Причем здесь имеется в виду ответственность за результаты реализации власти в целом. Хотя достаточно часто отмечалось, что далеко не все политические события являются результатом реализации власти, необходимо учитывать и более широкий набор социальных, психологических и политико-экономических факторов [Ледяев 2001: 354]. Здесь усматривается определенная ловушка. Демонстрация своего могущества и того, что все блага идут только от правящей политико-административной элиты, безусловно, повышает рейтинги и делает тех, кто может оспорить их статусные позиции, не более чем статистической погрешностью. Но есть и другая сторона. В кризисные периоды у правящей элиты не получится распределить ответственность и тем самым защитить себя от критики. В массовом сознании они будут считаться ответственными за все происходящее.

Видимое расхождение результатов проведенных социологических замеров заметно в вопросе о дебюрократизации государственного аппарата. В 2016 г. на проведении дебюрократизации управления настаивали 36,9\%, в 2018 г. этот показатель упал до 16,0\%. Такой результат можно интерпретировать следующим образом. Определенные действия по дебюрократизации предпринимались (такие, как оптимизация штатного расписания государственной гражданской службы, сокращение числа государственных служащих, внедрение современных информационных технологий), и об этом достаточно хорошо известно. Но есть и парадоксальное на первый взгляд объяснение экспертов, что дебюрократизация опасна как раз в кризисный период. Причем данная опасность выступает, с одной стороны, как выход на рынок труда большого числа безработных из числа бывших государственных служащих, а это проблемы по трудоустрой- 
ству и рост социальной напряженности, а с другой - как ослабление государственного аппарата и его управляемости. Вызывает тревогу также снижение «плотности» контроля различных сфер общества по мере развития кризиса.

Мало изменился и уровень оценки значимости кадровой работы и возможности добиться в ней кардинального улучшения работы системы профессиональной переподготовки и повышения квалификации кадров государственного и муниципального управления. Принципиальное улучшение кадровой работы именно на уровне элиты, хоть и не на самых первых позициях, считают возможным достаточно большое число экспертов.

Анализируя ответы экспертов на вопрос: «Какие достоинства и негативные характеристики проявляются в деятельности современных российских политико-административных и региональных элит?» - можно отметить ряд расхождений, например, снижение значимости умения разрешать конфликты: 44,50\% 3 года назад и $38,0 \%$ в настоящее время. Хорошо известно, что любой кризис формирует большее число различных проблемных ситуаций, которые требуют навыков быстрого управленческого реагирования и их эффективного разрешения. По логике, должен быть рост значимости данного качества представителей элиты, а не его снижение. То, что экспертный опрос показывает обратный результат, на наш взгляд, свидетельствует не о переоценке функций элиты, а об изменении понимания сути кризисных проявлений и принципиальной способности повлиять на них со стороны региональных элит. Конфликты и локальные кризисные проявления на региональном уровне продуцируются политическими и экономическими явлениями глобального порядка, на которые региональная элита не имеет возможности реально повлиять. Поэтому происходит снижение качественных оценок региональной элиты со стороны экспертов. При этом в массовом сознании представление об ответственности региональной политико-административной и бизнес-элиты за все, что происходит в данном регионе, остается неизменным, и оно достаточно критично.

Схожая картина просматривается и в ответе на вопрос об умении представителей элиты лоббировать интересы региона. В 2016 г. 23,50\% экспертов отмечали необходимость именно этого качества, а в 2018 г. на это указали только 12,0\%. Объяснить подобные оценки можно тем, что в 2016 г.у была более масштабная ресурсная база, более широкие инвестиционные возможности, постоянно росла конкурентность. За ресурсы и заказы можно было бороться, чтобы получить больше средств для развития региона. Сейчас ресурсная база и лоббистские возможности снижаются, и эта функция, которая была одной из важнейших в условиях экономического роста, в настоящее время, по мнению экспертов, уходит на второй план. Решение большинства системных проблем под воздействием глобальных факторов, создающих проблемы на региональном уровне, уже слабо зависят или вообще не зависят от лоббистских способностей региональных элит.

Заслуживают внимания ответы вопрос о значении чуткости представителей элиты к социальным проблемам. В 2016 г. значение этого фактора отмечали $13,75 \%$ экспертов, сейчас речь идет всего лишь о 6,0\%. При этом возрастает значимость факторов, связанных с необходимостью жестких и непопулярных решений для того, чтобы минимизировать значимость неопределенностей и рисков в будущем. Чуткость в смысле «войти в положение обездоленных» принятие подобных решений существенно затрудняет, хотя этот фактор может сам по себе вызвать дополнительные проблемы уже в отношении элиты и обычных людей. Разрешить данную коммуникативно-политическую проблему может демонстрация элитой реального принятия на себя всех издержек кризиса вместе с простыми людьми, и здесь не должно быть попыток создать для себя, 
используя возможности и статус принадлежности к элите, какие-либо более комфортные условия. Можно сказать, что наблюдается расхождение «экспертного» и «народного» понимания данного вопроса. Массовый социальный запрос на подобную чуткость к проблемам простых людей, по мнению экспертов, - это проявление определенной слабости, при которой будет невозможно быстро принимать непопулярные, но нужные решения. Это свидетельствует о формировании мобилизационного типа сознания, в котором происходящие процессы, связанные с санкционными действиями США и ЕС, их последствиями в виде проблем в экономике и падения уровня жизни, воспринимаются в обществе как «война», которая требует мобилизационной перестройки сознания и отношения.

Учитывая специфику современной ситуации, определяемую усилением санкционного давления и развитием связанных с ним кризисных явлений, в этот раздел исследования были добавлены 2 вопроса. В ответах на них мы видим, что $8,0 \%$ респондентов считают важной способность эффективно противостоять кризисным проявлениям, столько же отмечают необходимость проявления представителями элиты самого различного уровня принципиальности в отношении секторальных и индивидуальных дискриминационных санкций. В этих условиях эксперты считают, что в качестве механизма самозащиты общества в целом и элиты в частности будут заметны попытки работать на усиление «дружбы народов» как способ избежать усиления межнациональных конфликтов и защиты национальной безопасности (34,0\%). Тренд усиления патриотической составляющей и связанные с ней информационные кампании отметили $22,0 \%$ экспертов.

Современный кризис, по мнению экспертов, может привести к появлению опасных для общества моментов. Например, 14,0\% экспертов полагают, что будет усиливаться коррупционная составляющая. Считается возможным также усиление религиозной составляющей в жизни общества. На этот фактор обратили внимание $12,0 \%$ экспертов. Церковь и религия видятся институтами, формирующими возможности найти спокойствие и утешение, «отключиться» от существующих проблем. Обращение народа к религии в этом контексте может быть полезным правящей политико-административной элите - как способ переключить общественное сознание в безопасную для себя сферу.

В качестве изучения перспектив развития различных идеологических трендов представляет интерес оценка экспертами возможностей роста сепаратизма. В большинстве субъектов РФ эта проблема не является актуальной, но в республиках Кавказа опасность межрелигиозной конфликтности высока, хотя пока не получает адекватной оценки.

Представляет интерес оценка экспертами в 2018 г. значения факторов, снижающих эффективность работы региональной политико-административной элиты с учетом новых факторов и вызовов. Здесь по всем позициям практически полные совпадения с результатами исследований прошлых лет. При этом в условиях кризиса практически перестал играть существенную роль фактор недостаточной поддержки регионов со стороны федерального центра. Если значимость этого фактора в 2014 г. отмечали 28,41\% экспертов, сейчас - только 4,0\%. Реализация проектов по импортозамещению, более активное вмешательство федеральных властей в региональные политико-управленческие процессы дают основание считать, что, по крайней мере, вниманием со стороны центральной власти регионы не обделены.

Ответы на другие вопросы позволяют уточнить данную экспертную оценку и выявляют неоднозначность характера взаимодействия центра и регионов в условиях кризиса. Так, повысилось значение фактора, связанного с недостат- 
ком ресурсов в регионах для их социального и экономического развития. Нет кардинального решения вопроса о перераспределении налоговых средств в пользу регионов. Упоминавшаяся выше политика поддержки импортозамещения носит все-таки ограниченно-избирательный характер. Недостаток средств на развитие регионов в 2014 г. отмечали 44,76\% респондентов, а сейчас $-52,0 \%$. Повышается уровень внимания к рискам, которые связаны с коррупцией, хотя отмечается усиление политики противодействия этим деструктивным явлениям. Тем не менее опасность коррупционного фактора не снижается, а в чем-то даже нарастает. Если в 2014 г. опасность коррупции для эффективного функционирования политико-административной элиты отмечали 39,74\%, то в 2018 г. об этой опасности говорят уже 52,0\% экспертов.

Состояние кризиса повышает актуальность единства элиты и народа, способности обычных людей с пониманием относиться к непопулярным решениям и принимать неизбежные издержки. Но это возможно, если власть едина с народом. В 2014 г. опасность отрыва власти от народа отмечали 27,69\% экспертов, в современных условиях этот негативный для стабильности общества фактор выделяют уже 32,0\%. Огромный разрыв в доходах, социальное расслоение, непродуманные законодательные и управленческие инициативы усиливают отчуждение элиты, создают благоприятную среду для политических манипуляций, порождают опасные для политического строя и государства риски.

Результаты социологического опроса показывают определенную стабилизацию в кадровой сфере. В 2014 г. отсутствие должной системы кадровой политики федерального центра как значимую проблему отмечали $31,0 \%$ экспертов. В 2018 г. на наличие такой проблемы указали лишь 8,0\% экспертов. Федеральные программы по повышению квалификации, отбору кадров показывают, что система кадровой работы на федеральном уровне в определенной мере уже сложилась, существует и достаточно активно функционирует. Куда большую озабоченность вызывает региональный уровень, хотя и здесь отмечаются положительные сдвиги. В 2014 г. отсутствие должной системы кадровой политики в регионах отметили 29,7\% экспертов, в 2018 г. - лишь 14,0\%.

Можно также отметить резкое снижение значения общественного контроля за действиями представителей победивших на выборах партий. Если в 2014 г. проблема отсутствия эффективности контроля за просчетами победивших на выборах партий волновала 32,7\% экспертов, то в 2018 г. на значимость этого вопроса указали только 4,0\% экспертов, что можно объяснить системным кризисом партийной системы и признанием невозможности создать действенные системы контроля партии за качеством работы ее представителей.

Важнейшей функцией правящей элиты является способность проявлять стратегическое предвидение, создавать и реализовывать инновации в различных сферах жизни. Исследование показало недоверие экспертов к качеству реализации представителями элиты данной функции. Подавляющее большинство экспертов не видят у элиты необходимых качеств в отношении успешной инновационной деятельности. В связи с этим проявляется тревога: кто тогда сможет реализовать инновационную стратегию развития России, или страну ожидает стагнация, а затем и возможный упадок?

В условиях кризиса важным является вопрос о возможности кардинальных изменений существующей в стране системы общественно-политических отношений. Ответ экспертов на вопрос: «Какова вероятность такого рода кардинальных трансформаций в ближайшие годы?» - показывает, что значительная их часть (более 60\%) не верят в возможность изменений, предполагающих кардинальный слом существующей сейчас системы общественно-политических отношений, или отмечают их очень невысокую вероятность. Однако более $20 \%$ 
экспертов считают возможность изменений революционного характера равной 50\%. 18,0\% экспертов считают вероятность таких изменений высокой или очень высокой. Это показатель серьезный и достаточно тревожный.

Эксперты указали на приоритетные, с их точки зрения, возможности улучшения отбора и подготовки представителей региональной политико-административной элиты. Так, например, возможность качественно обновить и повысить эффективность политико-административной элиты видится в привлечении молодых специалистов из числа муниципальных и региональных лидеров и активистов, проявивших свою активную жизненную позицию.

Эксперты считают, что необходимо проводить отбор в элиту путем оценки по итогам мониторинга результатов эффективности работы руководителя, использовать проектную работу как способ отбора и подготовки политических лидеров, наставничество, стажировки и т.д. Отбор в управленческую элиту следует производить исключительно из числа претендентов, уже проявивших себя на практике и заслуживших авторитет у населения, исключить сращивание политиков и местных надзорных органов территорий и устранить практику круговой поруки и кумовства.

Если обобщить полученные пожелания экспертов, то можно сформулировать комплекс мер по следующим тематическим направлениям дальнейшей работы.

1. Необходимо продолжить изучение системы взаимоотношений элиты и широких слоев населения, тем более в условиях, когда кризисные явления создают угрозу методам такого взаимодействия, которые в стабильных условиях считались эффективными. Повышенное внимание уделять моделированию межэтнического взаимодействия.

2. Эксперты считают важным изучить возможность влияния элиты на социально-политические вопросы, связанные с безопасностью, образованием, патриотическими ценностями и вопросами юридической незащищенности граждан вне круга элиты.

3. В качестве перспективного направления исследований предлагается выделить вопросы, связанные с рассмотрением особой роли власти в становлении российской элиты, а также проблему «корней» элиты, нацеленной на служение своему Отечеству, воспитания чувства национального самосознания. Необходим постоянный анализ специфики внутренней идентификации современных российских элит и дифференциации элитного слоя по экономическим и политическим составляющим, механизма самовоспроизводства элиты и его влияния на качественный состав элитного слоя общества.

4. Осуществить разработку национальной концепции элиты, которая включала бы в себя когнитивные механизмы изучения передового опыта лидеров региональной российской элиты, диагностирование современного состояния российской элиты, перспектив ее развития, роли элиты в современном обществе и результатов влияния политико-административной элиты на развитие страны.

5. Развитие институциональной и ресурсной базы российской элитологии, исследовательских возможностей элитологии как отрасли научного знания в целом.

Реализация указанных мер позволит решать комплекс прикладных задач и разработать актуальные практические рекомендации по устранению проблем, возникающих в ходе государственного и муниципального управления.

\section{Список литературы}

Ледяев В.Г. 2001. Власть: концептуальный анализ. М.: РОССПЭН. 384 с. Локота О.В., Шутов А.Ю., Еремеев С.Г., Понеделков А.В., Шабров О.Ф., 
Буров А.В., Старостин А.М., Воронцов С.А., Коваленко В.И., Охотский Е.В., Григорян Д.К., Горбунов А.А., Черкасова Т.П., Карабущенко П.Л., Змияк С.С., Новожилов С.А., Ляхов В.П., Моисеев В.Н., Овчиев Р.М., Евтушенко С.А., Усманов Р.Х., Голубева М.О., Яланский А.П. 2016. Элитология и стратегии развития современной России: информационно-аналитические материалы Второго всероссийского элитологического конгресса. 21-22 октября 2016 г. Ростов-наДону. Ростов н/Д: Изд-во ЮРИУ РАНХиГС. 928 с.

Рудой В.В., Шутов А.Ю., Понеделков А.В., Старостин А.М., Воронцов С.А., Черкасова Т.П., Змияк С.С., Кузина С.И., Ляхов В.П. 2013. Современные региональные элиты (социологический анализ). Ростов н/Д. Изд-во ЮРИУ РАНХиГС. $184 \mathrm{c.}$

Тойнби А.Дж. 1991. Постижение истории (пер. с англ.). М.: Прогресс. 736 с.

PONEDELKOV Aleksandr Vasil'evich, Dr.Sci. (Pol.Sci.), Professor; Head of the Chair of Political Science and Ethnopolitics, Russian Presidential Academy of National Economy and Public Administration (bld. 1, 82 Vernadskogo Ave, Moscow, Russia, 119571; ponedelkov@skags.ru); Honored Scientist of the Russian Federation

VORONTSOV Sergei Alekseevich, Dr.Sci. (Legal), Professor of the Chair of Procedural Law, Russian Presidential Academy of National Economy and Public Administration (bld. 1, 82 Vernadskogo Ave, Moscow, Russia, 119571; raven_ serg@mail.ru)

OKHOTSKY Evgeniy Vasil'evich, Dr.Sci. (Soc.), Professor of the Chair of Public Administration, Faculty of Management and Politics, Moscow State Institute of International Relations, University of the Ministry for Foreign Affairs of Russia (76 Vernadskogo Ave, Moscow, Russia,119454; e.ohotskii@mail.ru), Second Class Adviser to the Diplomatic Service of the Russian Federation

VAS'KOV Maksim Aleksandrovich, Dr.Sci. (Soc.), Professor; Leading Researcher at the Laboratory for Problems of Increasing the Efficiency of State and Municipal Government, Russian Presidential Academy of National Economy and Public Administration (bld. 1, 82 Vernadskogo Ave, Moscow, Russia, 119571; vaskovmaxsim@mail.ru)

\title{
RUSSIAN ELITOLOGY: INNOVATIVE RESPONSES TO THE CHALLENGES OF THE MODERN WORLD
}

\begin{abstract}
The article explores possible innovative responses from the Russian elitology to the challenges of the modern world, analyzes the results of the sociological study that continues the long-term scientific tradition of the Rostov scientific elitological school to study the social status, role and basic characteristics of the modern Russian ruling elite, trends and problems of its development and functioning. The paper formulates a set of measures aimed at solving applied problems and develops practical recommendations for the elimination of problems arising in the course of state and municipal administration.
\end{abstract}

Keywords: elite, congress, case study, experts, conclusions, suggestions 